The limits of public communication coordination in a nuclear emergency: lessons from media reporting on the Fukushima case

This content has been downloaded from IOPscience. Please scroll down to see the full text.

2016 J. Radiol. Prot. 36 S45

(http://iopscience.iop.org/0952-4746/36/2/S45)

View the table of contents for this issue, or go to the journal homepage for more

Download details:

IP Address: 193.190.187.220

This content was downloaded on 07/06/2016 at $12: 23$

Please note that terms and conditions apply. 


\title{
The limits of public communication coordination in a nuclear emergency: lessons from media reporting on the Fukushima case
}

\author{
Iztok Prezelj ${ }^{1}$, Tanja Perko ${ }^{2}$, Marie C Cantone ${ }^{3}$, \\ Eduardo Gallego ${ }^{4}$, Yevgeniya Tomkiv ${ }^{5}$ and \\ Deborah H Oughton ${ }^{6}$ \\ ${ }^{1}$ University of Ljubljana, Faculty of Social Sciences, Ljubljana, Slovenia \\ 2 Belgian Nuclear Research Centre SCK · CEN, Institute for Environment Health and \\ Safety, Mol, Belgium \\ ${ }^{3}$ University of Milan, Faculty of Medicine, Milano, Italy \\ ${ }^{4}$ Universidad Politécnica de Madrid, Madrid, Spain \\ 5 Norwegian University of Life Sciences, Ås, Norway \\ ${ }^{6}$ Norwegian University of Life Sciences, Ås, Norway \\ E-mail: iztok.prezelj@fdv.uni-lj.si
}

Received 23 September 2015, revised 3 April 2016

Accepted for publication 18 April 2016

Published 6 June 2016

\begin{abstract}
Coordination of public communication has become a key issue in management of complex emergencies, and is a matter of debate between nuclear emergency management professionals. A particular problem is when inconsistent information is sent to the media and public by official sources from different levels, which has led to calls for a more coordinated approach. The IAEA created guidelines recommending a one-voice communication approach that provides clear, consistent and coordinated information by relevant stakeholders. The reviewed theory on the emergency communication coordination and the empirical results in this paper demonstrate some challenges regarding the feasibility of the above stated goal. This paper explores the communication process in the two-month period of the Fukushima nuclear emergency by using a quantitative comparative content and discourse analysis of 1340 printed media articles on the Fukushima nuclear disaster from two major newspapers in Spain ('El País' and 'El Mundo'), Italy ('Corriere della Sera' and 'La Repubblica'), Norway ('Aftenposten' and 'Dagsavisen'), Slovenia ('Delo' and 'Večer'), Belgium ('Le Soir' and 'De Standaard') and Russia ('Komsomolskaya Pravda' and 'Izvestiya'). The results show that it will be difficult to achieve a truly coordinated approach and one-voice
\end{abstract}


communication in severe nuclear and radiological emergency due to the communication difficulties created by the dispersion of information sources, a broad and dispersed focus of the reported information, partially subjective and conflicting media reporting. The paper suggests ways to improve public communication coordination in nuclear and radiological disasters.

Keywords: nuclear emergency, crisis, communication, coordination, Fukushima, media

(Some figures may appear in colour only in the online journal)

\section{Introduction}

The Fukushima Daiichi nuclear accident in Japan in 2011 was the subject of an enormous and global media coverage. The accident was newsworthy for a long period of time for both traditional and new media. Mass media were the first and main information channel related to Fukushima for the general public worldwide. Informing on nuclear emergencies is not just a matter of satisfying media needs, it is about the life and health of populations and the environment. According to the Aarhus or UNECE Convention (1998), all publics (affected or non-affected, local or in other countries) have the right to be informed about matters related to health and the environment, and public institutions are obliged to immediately disseminate information related to an imminent threat to human health or the environment. However, a review of lessons from Fukushima and other nuclear and radiological emergencies showed that public communication is one of the most important challenges in emergency management (IAEA 2013, p 29, Tateno and Yokoyama 2013). One of the typical mistakes in the past was that different official sources from different levels issued inconsistent information to the media and public. This inconsistency, with contradictory statements often being released at the same time, confused the public (IAEA 2012a, p 25). An example of such an inconsistency after Fukushima is the communication about the severity of the emergency from the Japanese official sources (mostly Tokyo Electric Power Company, TEPCO and the Government), the International Atomic Energy Agency (IAEA) and other relevant institutions.

Such findings make coordination of public communication a key issue in the management of nuclear and radiological emergencies. The main question is how to coordinate several emergency actors from different levels and their messages to the public in a short time period in order to provide clear and usable information for the directly and indirectly affected publics. IAEA (2012a, p 5, 27) stressed the need to improve emergency coordination in general and in particular in provision of information to the media, including material that promptly addresses public and media concerns. Such recommendations and the above mentioned lessons are not surprising because they correspond to similar calls in other non-nuclear fields of crisis management, national security and counter-terrorism. In fact, coordination has become a mantra of public administration after 9/11 (see Prezelj 2014) and coordination mechanisms for emergency management were considerably improved as a result, but the situation is still far from satisfactory at the level of interorganizational cooperation and coordination. Experiences from counterterrorism suggest that truly effective interorganizational cooperation seems like a holy grail: ever sought, but never really found (Prezelj 2015).

The following research question is addressed in this article: Is coordination of public communication in the case of a large nuclear or radiological emergency possible and to what extent can it be implemented? In order to address the research question an analysis of the 
mass media reporting on the Fukushima nuclear emergency in six countries (Belgium, Italy, Norway, Russia, Slovenia and Spain; two quality newspapers in each country, 1340 articles altogether) during the two month period after the accident (March 11th-May 11th 2011) was conducted. Nuclear or radiological emergencies occur in a global society with many communication actors, multiple interests, large and increasing number of media and a broad spectrum of publics with their own perspectives and needs. Many good interagency solutions for addressing complex problems have faced only partial success due to unpredicted problems of both system and human nature. The literature review in this paper shows that despite strong recommendations to adopt a more coordinated approach to public information in the case of a nuclear or radiological disaster, several existing problems need to be considered if this aim is to be realised.

The term 'communication coordination' in this article refers to the capacity to create and deliver a shared interpretation in support of achieving common goals. This interpretation has been derived from Comfort's (2007, p 194) understanding that communication in practice necessarily involves the capacity to create shared meanings among individual organizations and groups and coordination relates to achieving common goals.

The paper has the following structure: first, we introduce the theoretical and practical background on the need to maintain and improve operational and public communication coordination in case of nuclear and radiological emergencies and then, in the next section, we open the Pandora's box by reflecting on the theoretical and practical reservations about communication coordination, and introduce the study hypothesis. After presenting the methodology for the empirical studies, we present results and in the conclusion we identify theoretical and practical lessons about the limits of public emergency communication coordination in Fukushimalike nuclear or radiological events.

\section{Theoretical and practical background on public communication coordination in a nuclear and radiological emergency}

Public communication coordination in a nuclear and radiological emergency should be first discussed in the wider framework of emergency and crisis management. Complex nuclear and radiological emergencies inevitably lead to complex reactions by a number of local, regional, national and international governmental and non-governmental actors. Most emergencies are local events, but many of them escalate to the national and international level, having a strong influence on the number and spectrum of participating actors. Especially, nuclear and radiological events have a high potential to instantly become international problems due to high politicization, possible high radiation exposures and cross border effects, long lasting radiological and socio-psychological consequences. Disaster management researchers first addressed this problem in the seventies. For example, Dynes (1974, p 54) and Stallings (1978) found that the number of participating actors increases with the complexity and intensity of an emergency. This institutional complexity has a vertical and horizontal dimension (Stern 1999, pp 14-18). The vertical dimension refers to the number of actors from different levels, while the horizontal reflects the number of actors within the same level (e.g. various ministries, various international organizations, etc). In extreme cases, authors have described the situation as over-response (Quarantelli 1989), organizational attack (Dynes 1974, p 106), mass attack by organizations (Wenger 1978, p 38) and mass institutional assault upon the emergency (Rosenthal et al 1991, p 225) where many institutions do many things. In such emergencies, many people have highlighted the importance of coordinating all participating actors and creating a multi-agency response network (Drabek 1987, p 286, Hillyard 2000) and 
integrated and comprehensive crisis management approach (Rosenthal and Kouzmin 1997, Comfort et al 2001).

The IAEA, as the global focal point for nuclear cooperation, also understands a nuclear or radiological emergency as a complicated event requiring multidisciplinary coordination, including coordination among national and international emergency response authorities. Several stakeholders are involved in the communication, such as governments, regulators, operators, international agencies, technical organizations, independent nuclear experts and the public. There are at least two publics: the directly affected public and the concerned but non-affected public (IAEA 2012b). IAEA safety standards for the protection of health, life and property require establishment of an adequate level of preparedness for nuclear and radiological emergency at local, regional, national and international level (IAEA 2002, p 2). Whilst these safety standards are not legally binding for Member States, they may be adopted by them. IAEA safety standards require establishment of arrangements (in the plans) for providing useful, timely, truthful, consistent and appropriate information to the public and media and arrangements for coordinating the provision of information to the public and to the news and information media in the event of nuclear and radiological emergency (IAEA 2002, p 31). According to a recent report, these arrangements should ensure a coordinated 'one voice' message (IAEA 2012b, p 11). The standards also require that response to such emergency must be well-coordinated among all responding organizations, including the operators, organizations from other states and IAEA $(2002, \mathrm{p} 1)$.

IAEA reviewed the communication experience in the Fukushima emergency and concluded that implementation of the Joint Radiation Emergency Management Plan (JPLAN) within the Inter-Agency Committee on Radiological and Nuclear Emergencies (IACRNE—a coordination mechanism among 17 international organizations, such as EUROPOL, INTERPOL, OCHA, EADRCC ${ }^{7}$ etc) 'led to a consistent and harmonized response, in particular in the area of public communication' (IAEA 2013, pp 14-39). However, the same report suggested that: (1) public communication in a nuclear and radiological emergency needs further improvement; (2) provision of clear, objective and understandable information to the public reduces public concern and contributes to the effectiveness of emergency management and (3) inconsistencies in information released to the public have the potential to cause fear and unnecessary actions. The call for sending coordinated and consistent messages (e.g. solutions like joint public statements among international organizations and consistent individual national statements) was repeated, including preparation of joint messages for various scenarios, etc. Based on Fukushima, IAEA also published a practical guidance to those responsible for keeping the public and media informed and for coordinating all sources of official information to ensure a consistent message is provided to the public before, during and after an emergency (IAEA 2012c, p 1). The goal is 'to provide the consistent message: one message many voices' (IAEA 2012c, p 55). The guidance refers to a broad range of local, national (such as ministries of health, transportation, environment, national security-related ministries, agriculture organizations, etc) and international communicators (IAEA, World Health Organization, Food and Agriculture Organization, World Meteorological Organization, and Nuclear Energy Agency (NEA) within OECD, etc). The guidance requires four kinds of information coordination to avoid contradictory messages and misinformation: (1) local—national, (2) national, (3) national-international (with other states, international organizations) and 4) supra-national (inter-international) organizational coordination. The latter refers to the coordination among

\footnotetext{
${ }^{7}$ European Police Office (EUROPOL), the International Criminal Police Organization (INTERPOL), the United Nations Office for the Co-ordination of Humanitarian Affairs (UN/OCHA), Euro-Atlantic Disaster Response Coordination Centre (EADRCC).
} 
the IAEA, WHO, FAO, WMO, NEA, etc. The guidance recognizes that information about the emergency will be available from multiple sources and most people as highly motivated receivers of information will actively seek it from multiple sources. 'If the messages from these sources is sufficiently similar, members of the public will tend to believe they can trust the content and reliability' (IAEA 2012c, p 56). IAEA also portrays relations with media as a partnership where mutually constructive relations play a crucial role, and perceives emergency relation as dependent on the pre-emergency contacts (IAEA 2012b, p 15).

\section{Theoretical and practical limitations of emergency communication coordination}

The literature reflects some serious theoretical and practical limitations with regard to the above stated goal of coordinated messages in nuclear and radiological emergencies as well as in other complex emergencies. We have grouped these into seven distinct, although often related issues.

1. Crisis management has become a 'wicked' problem because of the sheer 'un-ness' of crisis (unscheduled, un-expected, un-planned, un-pleasant, un-operational and often un-imaginable events). Consequently, crisis management is unable to abate escalating crises in increasingly risk-dominated societies (Kouzmin 2008). This means that it will be difficult to coordinate messages in unpredictable and extremely complex nuclear or radiological emergencies.

2. Due to the inherent high uncertainty in emergencies, risk communication and risk assessment do not simply contribute to managing existing hazards, but they also serve to constitute those very hazards (Kinsella 2012, p 254). The problem is that risk communication is uniquely situated in the grey area where technology, politics and culture intertwine. It is dependent on imprecise risk assessment methods (including quantitative methods) and the risk acceptability will be culturally determined (Mirel 1994). This means that there is likely to be different opinions and perspectives about the situation, which will add to the difficulties of coordinating information about the actual risk and the situation on the ground in the case of nuclear or radiological emergency.

3. Symbolic readiness based on written plans also undermines communication coordination in nuclear and radiological emergencies. Perry and Lindell (2003, pp 336-8) stressed that the problem with emergency planning has been excessive emphasis on the written plan that tended to draw attention away from the process of planning itself and the original objective of achieving community emergency preparedness. Possession of a written plan is an important part of, but not a sufficient condition for, community emergency preparedness. Community emergency preparedness was defined by Perry and Lindell as a comprehensive process where all relevant organizations need to be involved as a part of effective interorganizational coordination. McConnell and Drennan (2006) also stressed the limited value of the written plan and identified the problem of 'symbolic readiness' as a result of the tension between the ideals of pre-crisis preparedness and planning and the operational reality.

4. The population and related media (as people's voice) have been frequently neglected in the emergency planning process (in terms of contributing to the creation of plans and not in terms of objects for message transmission or reception). However, the citizens (especially the population-at-risk, local communities and media) and all interested stakeholders need to be involved in the planning process. This was also recommended by the International Nuclear Safety Group (INSAG) (IAEA 2006). Focusing on nuclear 
and radiological emergencies, the International Commission on Radiological Protection also recommended engagement with relevant stakeholders, including other authorities, responders, the public, etc in the planning phase (ICRP 2009, p 42), recognising that it will be otherwise difficult to implement the plan effectively during the response. Also from a human rights perspective, people have a right to be involved in processes that may profoundly affect them; and this can also improve the effectiveness of planning (Perry and Lindell 2003, p 345, McConnell and Drennan 2006, p 66). International experts assembled in one of the post-Fukushima conferences argued the best practices in crisis and risk communication should be partnership and listening to the audiences (Janoske et al 2013). This means that the public needs to be accepted as a legitimate and equal partner. All this also means that coordination of public communication in nuclear and radiological emergency without giving the media and the public a proper role in pre-planning will be difficult if not impossible to achieve.

5. A general trend in planning has been the emergence of the crisis of trust, i.e. decline of public trust in planning and planners in the field of emergency management. This trend is related to a general decline in trust in government, institutions and professions. Swain and Tait (2007, p 232) argued that the practice of 'public involvement' serves as a particularly pertinent example of how trust is embedded in planning work. Participatory approaches to planning arose in part as a reaction to 'traditional' modes of representative democracy but also dissatisfaction with scientific, technocratic and professionalised systems of planning. Planning practice was viewed as centralised and out-of-touch with the needs of the people; it had essentially lost the trust of the public (see Swain and Tait 2007, p 232). Participatory models of involvement were, in part, an attempt to reembed trust in planning, particularly through providing arenas in which 'the public' could contribute to the planning process. Nevertheless, this is not easily achieved and there are many examples of participatory practices that have failed to generate trust (see Hansson and Oughton 2013). Due to increased distrust by the public in regulators and policy-makers, it has been argued that a greater openness of the decision-making process is needed (including greater public participation in risk governance). The role of the media within the new model of regulation is important. But the problem is that rather than being more or less passive messenger of news they have become independent watch dogs. A number of journalists have become de-facto campaigners, taking stances on everything, including safety. They can also amplify risks (Lofstedt et al 2011, p 414). It should be noted that the media also have to fulfil the economic aspects of publishing or broadcasting, with 'if it bleeds, it leads' being a well-known phenomenon in journalism (Berkowitz 2008, Rupar 2010). With the way of reporting (framing of the event), media can create, shape and terminate a crisis (Berkowitz 2008, Kovach and Rosenstiel 2007, Wilson 1996). They represent, interpret, and construct. Moreover, for most people, information about the nuclear domain is not directly experienced, but rather learned through elite discourse and communication in the media (Boomgaarden and de Vreese 2007, Perko et al 2012). The way emergency actors and media communicate about the risk from a nuclear accident can directly and indirectly influence a management of a nuclear event.

6. Any kind of communication coordination in nuclear and radiological emergency will face problems and will be criticized. A special committee created by the National Research Council at the end of eighties in the US found out that there will always be some communication problems and conflicts in radiological emergencies because of widespread dispersion of responsibility for management of such emergency and the fact that many disputes are not about the facts, scientific data or the clauses in the law, but about the 
social values (Ahearne 1990). Emergency actors should anticipate criticism by the public, elected officials and the media no matter how effective are they in responding and communicating. Often this criticism will seem excessive and unfair-especially when viewed from the perspective of knowing how hard and well the institutions are working to respond to the crisis (Brown 2003).

7. Lessons from Fukushima confirm most of the above general limitations to coordination of public communication in nuclear and radiological emergencies. Slovic (2012, p 73) pointed in this respect that the Fukushima accident showed the communication is still a major problem and that public fear, anger, and distrust still exist. Since Chernobyl, communication has clearly improved, but the response to Fukushima indicates there is still a long way to go in developing future public communication plans. Also Tateno and Yokoyama (2013) found out that public communication in Japan turned out to be highly problematic. They identified challenges in smooth interaction between the public, experts and mediators in Japan and between the Japanese and international sources. There were many controversies regarding communication and the way of providing risk information (unclear or incorrect statements, lack of objectivity, unimportant information in the media, etc). The problem was also that the public did not trust the government, the experts, or the media, which created a considerable anxiety about radiation. The anxiety derived from distrust of the government and uncertainty about scientific information. Also Hagmann (2012) observed the limitations of risk management and risk communication in the case of the Fukushima disaster. The problem is that risk analysis methods can describe reality (through public communication) by very limited statements about the future, subjecting them to fundamental debate. The optimism that the situation will improve by interorganizational learning in the post-Fukushima period was considerably reduced by the sobering finding of some experts assembled by the IAEA. They warned that the initial enthusiasm of adoption of new communication initiatives is limited by the potential difficulty of sustaining these initiatives over long periods of time, particularly if the emergency communications plans are rarely invoked (IAEA 2012b, p 1).

The literature review in the previous sections shows that despite a strong theoretical and empirical need to adopt a more coordinated approach to public information in the case of a nuclear or radiological emergency, several problems need to be considered if this aim is to be realised. Our paper aims to empirically investigate the dichotomy between a repeated call for co-ordination and lack of recognition of the related problems and eventually draw some theoretical and practical lessons.

The following hypothesis is tested:

$\mathrm{H}$ : In the case of a large nuclear disaster, it will be difficult to achieve effective coordination of public information communication due to:

- numerous information sources transmitting the information on the event $(\mathrm{H} 1 \mathrm{a})$,

- very broad and dispersed focus of the reported information (H1b),

- partially subjective (H1c) and

- conflicting media reporting $(\mathrm{H} 1 \mathrm{~d})$.

Even if authorities or other agencies manage to co-ordinate the provision of information, clear, consistent and coordinated messages will become to some extent blurred in practice. This is because the recipients of public information will actually be exposed to a variety of information (varied focus of articles) from many sources (numerous media sources), presented in various objective and subjective forms (types of articles) and with conflicting and contradicting claims. Public communication coordination will also be difficult because all the variables 
mentioned above are likely to change with time. By testing this hypothesis through media analysis, we aim to assess the limits of the ideal concept in an imperfect and complex practice.

\section{Research method}

For testing our hypothesis on the difficulties of communication coordination we used the mixed method (qualitative and quantitative) comparative research design (Ragin 1994, Tashakkori and Teddlie 1998) and media content analysis (Macnamara 2007). Comparative research typically focuses on identifying differences and similarities among the sampled cases. With a large number of cases (in the case of our research, 1340 articles from 12 newspapers from 6 countries) 'it becomes increasingly difficult to establish familiarity with each case' (Ragin 1994, p 107), which led us to use a coding and quantitative approach.

Content analysis of printed media articles on Fukushima nuclear accident from two major newspapers in Belgium ('Le Soir' and 'De Standaard'), Italy ('Corriere della Sera' and 'La Repubblica'), Norway ('Aftenposten' and 'Dagsavisen'), Russia ('Komsomolskaya Pravda' and 'Izvestiya'), Slovenia ('Delo' and 'Večer') and Spain ('El País' and 'El Mundo') was conducted. This sample includes three small and three big countries that are geographically dispersed in Europe (countries from the East, West, North, South and South-Eastern Europe). These countries faced similar radiological consequences due to the Fukushima accident and each of them has a different status related to nuclear energy production: phase out (Belgium), referendum about (Italy), active (Spain, Russia, Slovenia), no-nuclear energy production (Norway). Two quality newspapers with good article database were analysed from each country.

\subsection{Sampling and coding}

Six national teams (which included two coders and one master coder) first created electronic databases of all articles published in the critical discourse moment (two month period after the beginning of the accident: from 11th of March until 11th of May, 2011) based on the two key words: 'Fukushima' and 'nuclear'. A total of 1340 articles from all countries were sampled (260 articles from Belgium, 270 from Italy, 133 from Norway, 172 from Russia, 190 from Slovenia and 315 from Spain) and coded by two coders in each country according to our research variables. Such a large number of articles needed to be coded in order to get a simplified quantitative reflection from a large population of articles. The cases in comparative analysis must be more or less comparable to each other and the coding procedure was used to achieve this. In order to increase the validity of coding, the assessments produced by two coders were checked and compared by a master coder in each country. In case of a difference in the results by the two coders, a consensual assessment was made among the coders and a final master database was made. Also the inter-coder reliability coefficient was calculated based on the Krippendorff's alpha (Krippendorff 2004). This is a reliability coefficient developed to measure the agreement between observers or coders.

\subsection{Information sources (H1a)}

For the purpose of testing the part of the hypothesis on the numerous information sources transmitting the information of the disaster, the variable on information sources in the emergency communication process was chosen. Identifying sources of information is an important 
part of defining the communication flow, by pinpointing the actors that have been communicating in order to send their message through media channels to the general public. The code of journalism assumes that a media article must refer to different sources of information, in order to present several views and depict the event taking different aspects into consideration. The coders' aim in our research was to find out which sources were referred to or quoted in each article and classify them in the three categories:

- the category 'Japanese information sources' included TEPCO, government, various ministries, NGOs, inhabitants, etc;

- the category 'Domestic information sources' included sources from the newspaper's home country, such as national government, various ministries, domestic nuclear safety authority, nuclear power plant operator or owner, nuclear research institute, etc;

- and the category 'External information sources' included sources other than domestic or Japanese, such as national governments of other countries, various ministries of other countries, Nuclear safety authority of other countries, Nuclear power plants, Nuclear research institutes, IAEA; WHO, UN, FAO, etc.

\subsection{Focus of the articles (H1b)}

For the purposes of testing part of the hypothesis on the broad and dispersed focus of articles, we used three indicators reflecting the articles' predominant focus. The first indicator concerned the emergency management phases of the cycle, such as preparedness for a possible nuclear disaster, response, and recovery actions and evaluation of the consequences. The second indicator concerns the main topic of the article, such as energy, health, protective actions related to food, nuclear technologies, accident effects other than health and food, other protective actions (not food), tsunami or earthquake, and nuclear or radioactive waste. And the third indicator concerns the geographic focus of articles, such Japan, domestic, another country, European or international.

\subsection{Article type (H1c)}

For the purpose of testing part of the hypothesis on various forms of presenting emergency information to the public, a variable on the article types was chosen. The following types of articles were coded: news (concise reports on the situation, which sticks to factual information), interviews (with relevant people often representing one point of view), editorials (as critical analysis of the current events and subjective opinion supported by facts), columns (as regular piece by the same author providing an opinion or different perspectives on the news item), features (in-depth look at what is going on behind the news, using a detailed description and analysis, several sources, etc), and letters (written by individuals from the general public or representing an organization). Articles where the description of the news was interspersed with quotes from various actors and personal views of the journalist or his sources were categorized as mixed. For the purpose of this paper, we classified news and features as objective articles, while interviews, editorials, columns and letters were classified as subjective articles. One half of the mixed type of articles was attributed to the objective and one half to the subjective category.

\subsection{Conflict or disagreement $(H 1 d)$}

For the purpose of testing this part of the hypothesis we chose the variable indicating the information on conflicts and disagreements related to the nuclear emergency. The coders identified 




Figure 1. Japanese sources of information by actors and countries.



Figure 2. External sources of information by actors and countries.

articles that explicitly mentioned some sort of disagreement or conflict about a nuclear emergency management or other related topic. Such disagreements could be reported in words (e.g. contradictive positions or claims) or in deeds (e.g. protests, stigmatisation, etc). Such articles can confuse the public and hinder efforts for effective public communication coordination (one emergency—one voice efforts).

\footnotetext{
${ }^{8}$ Interestingly, international organizations other than IAEA were almost not used as a source in the public communication about the Fukushima disaster. EU was used as the external source only in $9 \%$ of the articles with external sources, WHO in $6 \%$. FAO and OECD—NEA were almost not used as sources.
} 


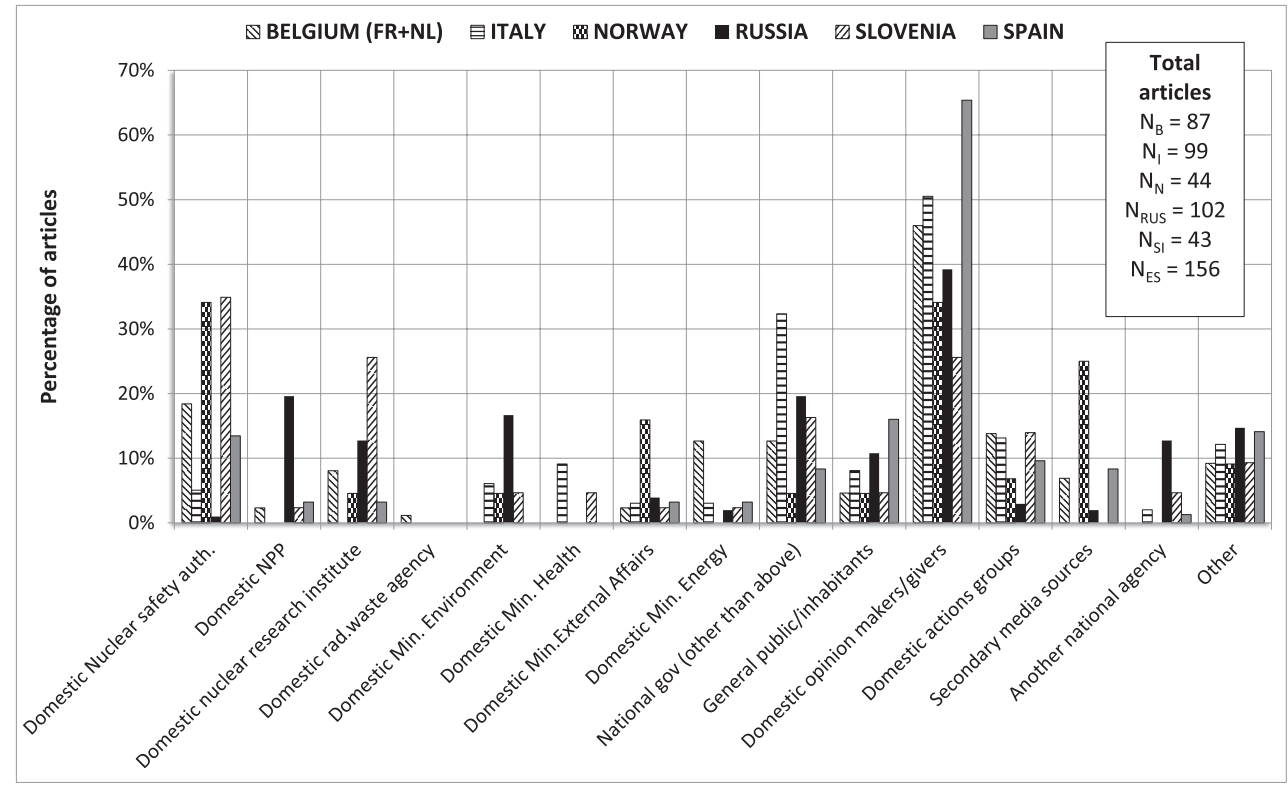

Figure 3. Domestic sources of information by actors and countries.

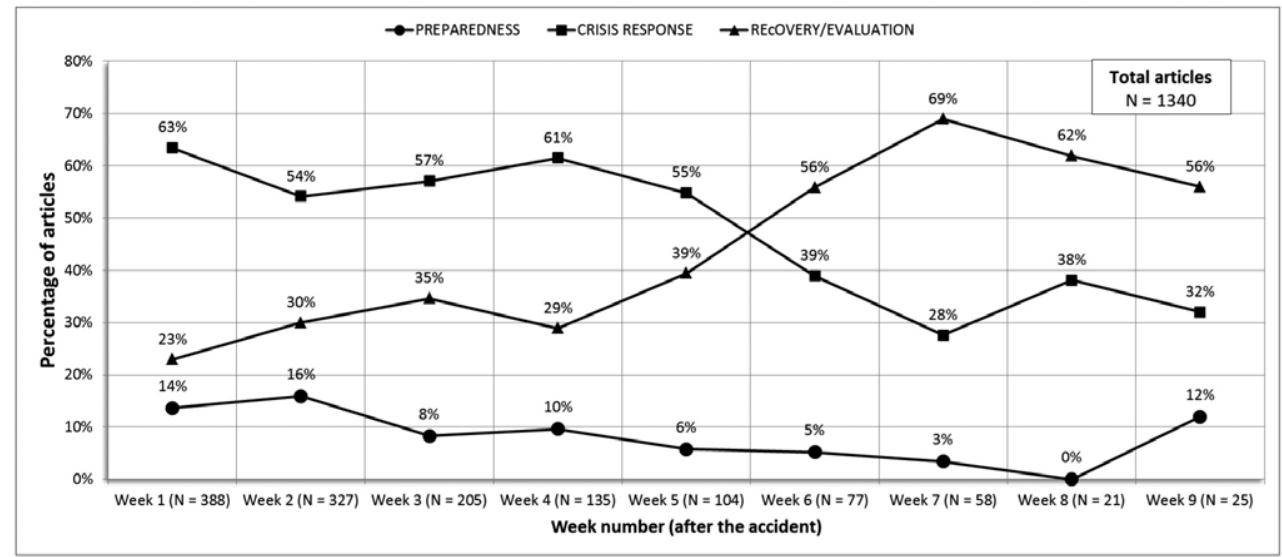

Figure 4. Percentage of articles focusing on parts of the emergency management cycle.

\section{Results}

A general overview of media reporting in six countries reflects a high media attention in the first weeks and gradual decrease of the media attention or newsworthiness of the event in time. Around 40 to around 100 Fukushima-related articles per country were published in the first week and less than 10 articles per country in the ninth week after the beginning of the accident. Additionally, the average number of words per article for all countries decreased from 510 words in the first week, down to 344 words in the ninth week after the incident. These indicators suggest that the need for coordinating public information, at least for the European countries, is much higher in the early phase of nuclear and radiological emergency than several weeks later. They also suggest that time dimension in testing our hypothesis is relevant. 


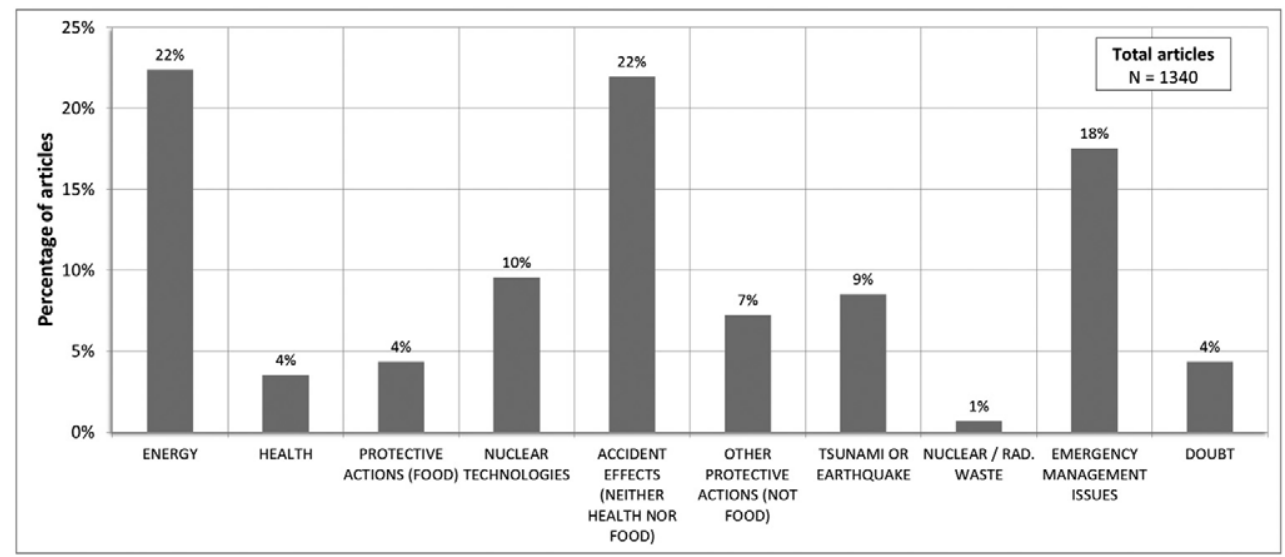

Figure 5. Focus of the published articles on the Fukushima.

\subsection{Numerous information sources transmitting the information on nuclear or radiological emergency (H1a)}

Media information consumers in the sampled countries received information about Fukushima from many Japanese, internal and external sources. Most of the articles simultaneously transferred information from more than three information sources. Approximately 40 percent of all articles in the sample (1340) used Japanese sources and the same percent used external and internal sources. Japanese sources had a stronger voice in Norway (50\% of articles) and Spain (49\%), while domestic sources were strong (59\%) and external sources were weak (24\%) in Russia. rom:

Figures 1-3 show that the public in the sampled countries received information mostly

- the following Japanese sources (522 articles): the government (67\% of all articles with the Japanese sources), Operator TEPCO (41\%), local inhabitants (25\%), mass media from Japan $(21 \%)$, emergency management actors (11\%) and Japanese opinion makers $(11 \%)$.

- the following external sources (521 articles): national governments of other states (27\% of all articles with external sources), opinion makers from other states (27\%), secondary media sources $(24 \%)$, IAEA $(23 \%)$ and nuclear safety authorities from other countries $(11 \%)^{8}$.

- the following internal sources (531 articles): domestic opinion makers (49\%), local national government (16\%) and domestic nuclear safety authority (14\%).

We selected the most frequent sources of information in the media of the sampled countries to see which voices were, quantitatively speaking, the most influential in spreading disasterrelated information to the public. The most frequent sources were selected if they were mentioned in more than 100 articles or represented more than $20 \%$ of all articles within the source type category. It turns out that the most influential media sources in the Fukushima disaster were:

- the Japanese government (22\% among the selected most important sources),

- domestic opinion makers (16\%),

- operator TEPCO (14\%), 
- external national governments (99\%),

- opinion makers from other countries $(99 \%)$

- Japanese inhabitants (8\%),

- secondary media sources from other countries $(88 \%)$,

- IAEA (88), and

- mass media from Japan (78\%).

This means that public information coordination predominantly needs to take into consideration a combination of the above identified specific domestic sources, external sources and sources from the affected country. The IAEA communication voice turns out to be just one of many communication voices. IAEA communication guidance argues for strong coordination among all sources of official information to ensure that a consistent message is provided to the public. Our results on the most important sources indicate that the media and the public in the sampled countries received information from only four official sources that could be coordinated as proposed: the Japanese government, the operator TEPCO, external national governments and IAEA. The other sources are not necessarily compatible with coordinated public communication in emergency. Opinion makers, either domestic or from other countries include scientists, activists, well-known personalities and politicians, whose opinion is considered important enough to be presented separately from official governmental opinions. Japanese inhabitants include all people living in Japan at time of this disaster. This group's views were reflected in the media. These groups, with exception of press agencies, normally represent themselves and do not confirm to the principle of communication coordination in non-emergency and emergency time.

When a time dimension was added to the information transmission from the sources, it was observed that the relevance of sources varied throughout the analysed time period. This reflects an additional complication for coordination of information providers as their newsworthiness obviously changes through time. Japanese sources were the most important sources in the third (30\% of all articles), fourth (29\%), fifth (31\%) and ninth (40\%) week and the least important in the seventh week (7\%) after the beginning of disaster. Domestic sources were the most important in the first week (31\% of all articles) and in the sixth week (34\%), while external sources maintained a presence in 20-30\% of articles throughout all nine weeks. The changing presence of sources in different weeks could depend on the reporting supply and information demand of the week. For instance, in week 7 and to some extent also in week 8 , the world remembered the 25th anniversary of Chernobyl, thus the journalists used more domestic and external sources than the Japanese sources.

\subsection{A very broad and dispersed focus of the published articles (H1b)}

Most of the articles in nine weeks after the outbreak of the emergency focused on crisis response (55\%). A considerable part of the articles focused also on recovery actions and evaluation of the consequences (33\%) and also on preparedness for such an emergency (11\%). There was a higher than average focus on preparedness in Spain (20\% of all articles) and Italy (13\%), on crisis response in Belgium (63\%), Russia (72\%) and Spain (66\%), and on recovery and evaluation in Italy (50\%), Norway (54\%) and Slovenia (45\%). Figure 4 shows that this focus changed over time. In the first 5 weeks, most articles conveyed information on the crisis response and then their attention shifted towards recovery and evaluation. Reporting on preparedness for such a disaster was modestly present all the time (except in week 8). 


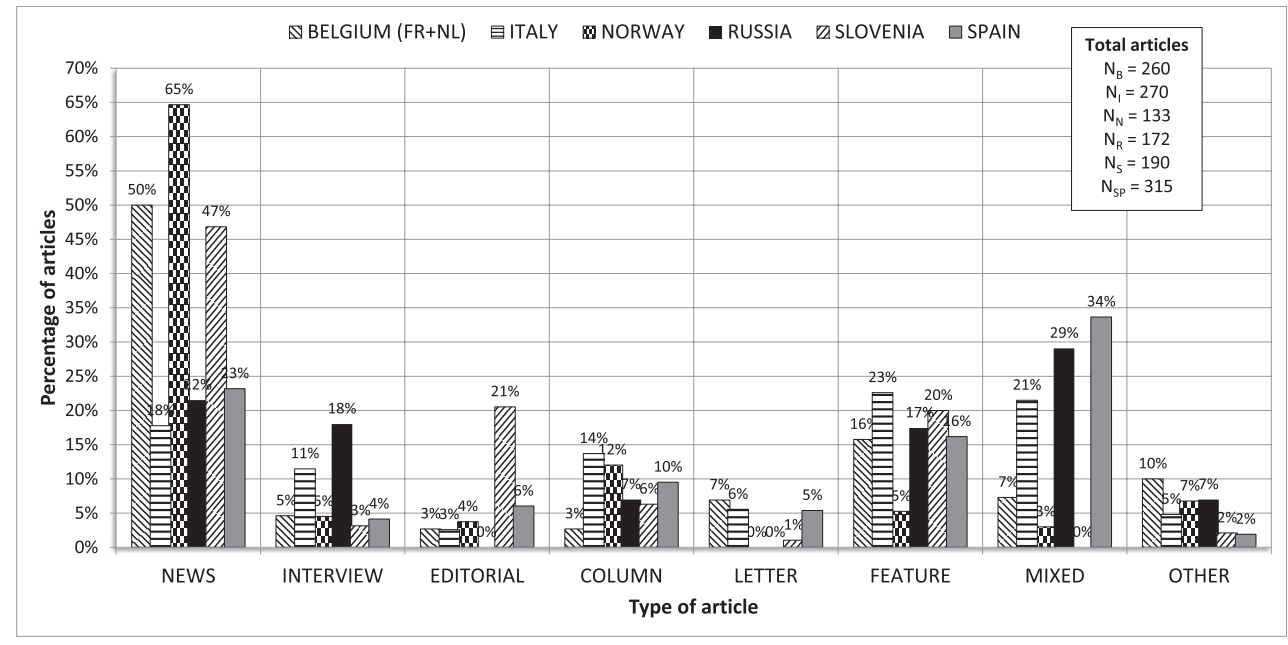

Figure 6. Different types of articles in the sampled countries.

The main topics of the articles were rather dispersed. The articles were coded into nine mutually exclusive categories. Figure 5 shows that three topics dominated the reporting: energy (22\% of all articles), accident effects other than health and food $(22 \%)$ and emergency management issues (18\%). These topics represented about two thirds of all articles and conveyed information about environmental and economic effects of the accident, emergency management problems (e.g. public information), problems with emergency workers or with other actors and also on the future of nuclear energy, energy shortage and supply issues. The rest of the articles focused on nuclear technologies (10\%), tsunami or earthquake (9\%), health (4\%), food protective actions (4\%), other protective actions (7\%) and nuclear or radiological waste $(1 \%)$. At least one third of the articles covered topics not directly related to the immediate emergency problems (energy, nuclear technologies and waste). The time analysis of these indicators showed a very complex picture with constant shifts in focus. It should be noted that in the first, seventh and ninth weeks, most of the articles conveyed information about energy, while in the fourth week, most of the articles reported on the accident effects (neither health nor food).

It is important to understand also the geographic dimensions of the focus dispersion in media reporting in the aftermath of the nuclear emergency. The results show that $53 \%$ of articles focused directly on Japan, while the rest of the articles focused on the international or global themes (18\%), domestic themes (17\%), another countries (8\%) or European themes (4\%). The focus on Japan prevailed during the whole period of our study except for week 7 , when international themes gained the highest focus. In terms of differences among countries, it was observed that Russia (35\%) and Italy (29\%) had relatively higher focus on domestic themes than other countries, with Norway (70\%) and Spain (61\%) focusing on Japan.

\subsection{Partially subjective media reporting on the nuclear and radiological emergency (H1c)}

In all sampled countries, most of the published articles were of the news type (35\%), followed by mixed type of articles (18\%), features $(17 \%)$, columns $(9 \%)$, interviews $(7 \%)$, editorials $(6 \%)$, letters $(4 \%)$ and other $(5 \%)$. The objective category of articles that includes news, 
features and one half of the mixed type of articles amounted for $59 \%$ of all articles. On the other hand, the subjective category of articles (interviews, editorials, columns, letters and one half of the mixed type) represented $35 \%$ of all articles. This means that approximately one third of the information about the Fukushima nuclear disaster was of a subjective nature. In terms of time analysis, it turned out that news articles were prevailing in all weeks except in week 7, when the need to remember Chernobyl and compare both disasters made features and mixed type the prevalent forms.

Figure 6 shows the distribution of article types per country, indicating that between 47 to $65 \%$ of all published articles in Norway, Belgium and Slovenia were news, that most of the interviews were published in Russia (18\%) and that most of editorials were published in Slovenia $(21 \%)$.

\subsection{Conflicting media reporting $(H 1 d)$}

One third of the articles transmitted information on conflicts related to the nuclear and radiological emergency. In all sampled countries, $32 \%$ of articles explicitly mentioned disagreement or conflict about the Fukushima nuclear emergency or related issue. The highest level of information on disagreements or conflicts was provided to the Italian public (44\% of all articles in Italy), followed by Slovenia (36\%), Belgium (32\%), Russia and Spain (27\%) and the lowest to the Norwegian public (20\% of articles). The time analysis showed a general increase of exposure to information on conflicts and disagreements from week 1 to week 7 (from $30 \%$ to $50 \%$ of all articles in all countries). The only exception here was Italy, where more than $60 \%$ of articles published by both Italian newspapers in week 3 explicitly transferred information on conflicts and disagreements. The Fukushima disaster opened a big debate in Italy about the future of nuclear activities in this country. After week 7, this had dropped in three countries (Norway, Russia and Italy) and increased in 3 countries (especially Spain, and also in Slovenia and Belgium). The highest level of information on disagreements or conflicts was detected in the articles focused on energy (49\% out of 300 articles), while the lowest level in the articles on tsunami or earthquake (12\% of 114 articles). It was also observed that on average $15 \%$ of all articles, which conveyed information on conflicts, contained information about conflicts in public communication. Most of such articles were published in Russia (23\%), Belgium (22\%) and Slovenia (16\%). The smallest number of such articles were published in Norway (7\%).

\section{Discussion}

The comparative study applied in this paper represents a good tool for assessing and advancing the initial theoretical and conceptual knowledge on the need for and limitations of public communication coordination in case of nuclear emergency. Ideal public communication in nuclear emergency is characterised by providing clear, consistent and coordinated information, or a 'one-voice communication approach', by relevant actors. Media play the role of partners in this process, and represent one of the partners who are most likely to understand emergency communication needs. The review of emergency communication coordination theory in this paper, introduced some concerns about the feasibility of the 'one-voice' communication goal. The empirical results in this paper support, confirm and deepen these theoretical and conceptual concerns. Based on this, we can confirm our overarching hypothesis on the presence of a number of specific factors that are likely to challenge coordination of information, including the sub-hypotheses on the dispersion of information sources, a broad and dispersed focus of the reported information, partially subjective and conflicting media reporting. 
The results on media reporting about Fukushima from six European countries suggest that only a limited public information coordination can be achieved in the case of a severe nuclear disaster. If these limitations are not recognised, we are likely to face a problem of 'symbolic readiness' (McConnell and Drennan 2006) and insufficient 'community emergency preparedness' (Perry and Lindell 2003) in the field of information coordination in case of severe nuclear emergencies. This also means that the mantra on clear, consistent and coordinated information, or a 'one-voice communication approach', which is continuously repeated by the IAEA (as a key authority in this field) (IAEA 2002, 2012b, 2012c, 2013), is promising a false reality and false expectations for the time of a new nuclear disaster. Clarifying the weakness of such a position is a significant step to avoid similar mistakes in the future.

It may sound paradoxical, but the evidence on the limitations in achieving effective comprehensive information coordination does not reduce the need for establishing such coordination, it only increases it. For example, theoretically and conceptually we know that media and relevant publics need to be included in the partnership of emergency planning processes (Perry and Lindell 2003, Perry and Lindell 2003, IAEA 2006, McConnell and Drennan 2006, Janoske et al 2013) in the field of emergency communication. Nonetheless, the empirical evidence from this paper suggests that it is impossible to integrate media at the global level with all its reporting needs (different views, opinions, the need for criticism). The nature of the public and media sphere will likely prevent effective coordination and one-voice communication. Supposedly coordinated messages will get blurred because the media sphere is not a simple one-way communication road, but a complex area that, by definition, will publish inconsistent and uncoordinated information. It is too complex (multiple levels, multiple actors and communication channels, various interests, in-built need for reporting conflicts and subjective views aside from objective views) to be controlled even in nuclear emergencies in terms of coordinating the production and transmission of consistent information. Even among the official sources, IAEA, the only global actor in this area, seems to be too limited to be or become a true universal coordinator of the nuclear emergency information. Furthermore, media integration in the 'one-voice communication approach' could appear like censorship from the perspective of the media. Whilst co-ordination might be theoretically possible in the affected country due to the serious emergency situation, it is not likely to be feasible in other non-directly affected countries, let alone at the global level. Consequently, authorities need to recognise that a range of objective and subjective uncoordinated messages will be published in the media, and this can result in a reduction in trust in the authorities by various publics.

Which specific limits of and what lessons for the public information coordination can be extracted from the results in this paper?

Firstly, media information consumers in the sampled countries received information about Fukushima from many Japanese, internal and external sources (H1a). The most influential sources were governmental sources that can be coordinated (the Japanese government, operator TEPCO, external national governments and IAEA). Other important sources found in the articles were not necessarily compatible with a coordinated public communication in emergency (opinion makers, such as scientists, well-known personalities and politicians from domestic or other countries, Japanese inhabitants, media from Japan and other countries and press agencies). The limitation in the present coordination concept is in the fact that the coordinators cannot coordinate (i.e. control) some of the very relevant information sources. In such a dispersion of information sources, the IAEA communication voice will be just one of the many. The conceptual lesson here is that effective public information coordination will need to find a coordination mechanism for all of the involved sources at the local, national and international level; otherwise, the coordinated information will remain only one of the voices. This means that local voices need to be coordinated also with international voices 
(and national ones). Otherwise each coordination attempt will remain partial in the sense that if coordination is not comprehensive then it is reduced to be considered as only one of many voices. Therefore, for the sake of realism, the fact of source dispersion needs to be taken into consideration in nuclear emergency planning at all levels. Such mechanisms will need to recognise that coordination of opinions about certain aspects of an emergency are unlikely to be achievable, but that processes for improved dialogue, such as in the planning phase, might avoid some inconsistencies.

Secondly, the results showed a broad and dispersed focus of all 1340 articles on the Fukushima disaster (H1b). In terms of the emergency management cycle, only slightly more than one half of the articles focused on the crisis response, while the rest of articles focused on recovery actions and evaluation of the consequences and also on preparedness for such disaster. The main topics of the articles varied widely in the six countries. The published information did not only concern the direct emergency effects of the Fukushima emergency, but also addressed other non-emergency topics such as energy shortage and supply, the future of nuclear energy, nuclear technologies, and nuclear waste. The focus of information also varied in terms of geography. Slightly less than half of the articles discussed nuclear issues from outside of Japan, such as other global themes, domestic themes, themes from another countries or European themes. This dispersion of focus suggests another conceptual lesson. The coordination of nuclear emergency information is likely to be influenced by other related topics in different geopolitical environments. Focus dispersion inevitably triggers an involvement of a big number of additional sources that will have to be acknowledged, even if they cannot be fully coordinated. The media actually 'ab'-use the on-going emergency to deal with other issues, which are important in geopolitical settings of the different countries. This fact exceeds the disaster-related competences and capabilities of the involved emergency coordinators of public information, and, can therefore, make their coordination efforts incomprehensive and short-term.

Thirdly, approximately one third of the information about the Fukushima nuclear disaster was of a rather subjective nature, because it was provided by interviews, editorials, columns, letters, etc (H1c). This partially subjective media reporting on the nuclear and radiological emergency is a big challenge for one emergency-one voice approach. It is in the nature of media in modern states to present different viewpoints and be subjective, because this increases their readership and influence. The conceptual lesson for the public information is that this subjectivity needs to be incorporated in the information coordination process at different levels, but without reducing the autonomy of the media.

Fourthly, one third of articles transmitted information on the various conflicts or disagreements in words or deeds related to the nuclear and radiological emergency (H1d). Such articles could confuse the public in the crisis time and hinder efforts for effective coordination of public communication (one emergency-one voice efforts). The conceptual lesson for the public information is that information coordination needs to address the problem of coordination of messages on the conflicts related to the nuclear emergency.

High media attention in Europe the first weeks after the beginning of the nuclear disaster suggests that the pressure for coordinating public information is much higher in the early phase of nuclear and radiological emergency than several weeks later when much less articles are being published. Although this will of course be situation and location dependent. Temporal variations in all of the above mentioned variables represent additional challenges for information coordination. The relevance of sources in transmitting information to the publics will change with time. The media focus is very broad but also constantly shifting. The prevalent media focus in the first five weeks was crisis response, but then the focus shifted to recovery and evaluation. The news is not necessarily the prevalent way of delivering 
information to the public at all times of the emergency. The time analysis also showed a general increase of exposure to information on conflicts and disagreements from week 1 to week 7 (from $30 \%$ to $50 \%$ of all articles in all countries), with exception of Italy. Time variations of all above discussed variables actually point to the need for a flexible information coordination mechanism that will be able to adapt to the changes of sources, changes in cyclic, topical and geographic focus, changes in the debated conflicts and changes in the needs for more subjective information.

To conclude, the results in this research suggest that public information coordination in a nuclear and radiological emergency will remain a challenge for a long time. But if the responsible actors want to improve their effectiveness and comprehensiveness, they should incorporate the lessons identified above in their nuclear and radiological emergency communication plans. The lessons can be also used as a basis for writing scenarios for the future nuclear disaster exercises, preferably in dialogue with a variety of different stakeholders, including the media.

\section{Acknowledgments}

The research leading to this study has received funding from the European Atomic Energy Community Seventh Framework Programme FP7 (as part of the project PREPARE—grant agreement 323287), the related Norwegian Research Council PREPARE project (226135) and its Centres of Excellence funding scheme (project number 223268/F50).

\section{References}

Ahearne J 1990 Telling the Public about risks Bull. At. Sci. 46 37-9

Berkowitz A D 2008 Reporters and their sources The Handbook of Journalism Studies ed K WahlJorgensen and T Hanitzsch (New York: Routledge) pp 102-15

Boomgaarden H G and de Vreese C H 2007 Dramatic real-world events and public opinion dynamics: media coverage and its impact on public reactions to an assassination Int. J. Public Opin. Res. $19354-66$

Brown T S 2003 Powerful crisis communications lessons Public Relations Q. 48 31-4

Comfort L 2007 Crisis management in hindsight: cognition, communication, coordination and control Public Adm. Rev. 67 189-97

Comfort L, Sungu Y, Johnson D and Dunn M 2001 Complex systems in crisis: anticipation and resilience in dynamic environmentas J. Contingencies Crisis Manage. Res. 9 144-58

Drabek T 1987 Emergent structures Sociology of Disasters ed D Russell et al (Newark: University of Delaware) pp 291-330

Dynes R 1974 Organized Behaviour in Disaster (Newark: University of Delaware)

Hagmann J 2012 Fukushima: probing the analytical and epistemiological limits of risk analysis J. Risk Res. 15 801-15

Hansson S O and Oughton D H 2013 The public participation: promises and pitfalls Societal and Ethical Aspects of Radiation Risk Management ed D H Oughton and S O Hansson (Amsterdam: Elsevier) pp 333-45

Hillyard M 2000 Public Crisis Management: How and Why Organizations Work Together to Solve Society's Most Threatening Problems (San Jose: Writers Club Press)

IAEA 2002 Preparedness and Response for a Nuclear or Radiological Emergency IAEA Safety Standards No. GS-R-2 (Vienna: International Atomic Energy Agency)

IAEA 2006 Stakeholder Involvement in Nuclear issues INSAG-20 (Vienna: International Atomic Energy Agency)

IAEA 2012a Lessons Learned from the Response to Radiation Emergencies (1945-2010) (Vienna: International Atomic Energy Agency)

IAEA 2012b IAEA Report on Enhancing Transparency and Communication Effectiveness in the Event of a Nuclear or Radiological Emergency (Vienna: International Atomic Energy Agency) 
IAEA 2012c Communication with the Public in a Nuclear or Radiological Emergency (Vienna: International Atomic Energy Agency)

IAEA 2013 IAEA Report on Preparedness and Response for a Nuclear or Radiological Emergency in the Light of the Accident at the Fukushima Daiichi Nuclear Power Plant (Vienna: International Atomic Energy Agency)

ICRP 2009 Application of the Commission's Recommendations for the protection of people in emergency exposure situations ICRP Publication 109 Ann. ICRP 39 (www.icrp.org/publication.asp?id=ICRP\%20 Publication\%20109) (Vienna: International Atomic Energy Agency) (accessed 2 May 2014)

Janoske M L, Liu B F and Madden S 2013 Congress report: expert's recommendations on enacting best practices in risk and crisis communication J. Contingencies Crisis Manage. 21 231-5

Kinsella W J 2012 Environments, risks, and the limits of representation: examples from nuclear energy and some implications of Fukushima Environ. Commun. 6 251-9

Kouzmin A 2008 Crisis management in crisis? Adm. Theory Prax. $30155-83$

Kovach B and Rosenstiel T 2007 The Elements of Journalism: What Newspeople Should Know and The Public Should Expect (New York: Three Rivers)

Krippendorff K 2004 Reliability in content analysis Hum. Commun. Res. 30 411-33

Lofstedt R, Bouder F, Wardman J and Chakraborty S 2011 The changing nature of communication and regulation of risk in Europe J. Risk Res. 14 409-29

McConnell A and Drennan L 2006 Mission impossible? Planning and preparing for crisis J. Contingencies Crisis Manage. 14 59-70

Macnamara J 2007 Media content analysis: its uses; benefits and best practice methodology Asia Pac. Public Relations J. 6 1-34

Mirel B 1994 Debating nuclear energy: theories of risk and purposes of communication Tech. Commun. Q. 3 41-65

Perko T, Turcanu C and Carlé B 2012 Media reporting of nuclear emergencies: the effects of transparent communication in a minor nuclear event J. Contingencies Crisis Manage. 20 52-63

Perry R W and Lindell M K 2003 Preparedness for emergency response: guidelines for the emergency planning process Disasters 27 336-50

Prezelj I 2015 Improving interorganisational cooperation in counterterrorism Public Manage. Rev. 17 209-35

Prezelj I 2014 Interorganizational cooperation and coordination in the fight against terrorism: from undisputable necessity to paradoxical challenges Comparative Strategy 33 321-41

Quarantelli E L 1989 How Individuals and Groups React During Disasters: Planning and Managing Implications for EMS Delivery (Newark: University of Delaware) DRC Paper

Ragin C 1994 Constructing Social Research: the Unity and Diversity of Method (Thousand Oaks: Pine Forge)

Rosenthal U and Kouzmin A 1997 Crises and crisis management: toward comprehensive government decision making J. Public Adm. Res. Theory 7 277-305

Rosenthal U, t'Hart P and Kouzmin A 1991 The bureau-politics of crisis management Public Adm. $69211-33$

Rupar V 2010 Journalism and Meaning-Making: Reading the Newspaper (New York: Hampton)

Slovic P 2012 The perception gap: radiation and risk Bull. At. Sci. 68 67-75

Stallings R 1978 The structural patterns of four types of organizations in disasters Disasters: Theory and Research ed E L Quarantelli (Beverly Hills, CA: Sage)

Stern E 1999 Crisis Decisionmaking: A Cognitive Institutional Approach (Stockholm: Universtiy of Stockholm)

Swain C and Tait M 2007 The crisis of trust and planning Plan. Theory Pract. 8 229-47

Tashakkori A and Teddlie C 1998 Mixed Methodology: Combining Qualitative and Quantitative Approaches (London: SAGE)

Tateno S and Yokoyama H 2013 Public anxiety, trust, and the role of mediators in communicating risk of exposure to low dose radiation after the Fukushima Daiichi nuclear plant explosion J. Sci. Commun. 12 1-22

UNECE 1998 Convention on Access to Information, Public Participation in Decision-Making and Access to Justice in Environmental Matters (Denmark: Arhaus) (http://ec.europa.eu/environment/ aarhus/) (accessed 30 September 2013)

Wenger D 1978 Community response to disaster: functional and structural alternations Disasters: Theory and Research ed E L Quarantelli (Beverly Hills, CA: Sage)

Wilson J 1996 Understanding Journalism (New York: Routledge) 